\title{
Mediation in the Construction of Mathematical Knowledge: A Case Study Using Dynamic Geometry
}

\author{
Gilmara Teixeira Barcelos ${ }^{1}$, Silvia Cristina Freitas Batista ${ }^{1}$, \\ Liliana Maria Passerino ${ }^{2}$ \\ ${ }^{1}$ Instituto Federal de Educação Ciência e Tecnologia Fluminense, Campos dos Goytacazes, \\ Rio de Janeiro, Brazil; \\ ${ }^{2}$ Universidade Federal do Rio Grande do Sul, Porto Alegre, Rio Grande do Sul, Brazil. \\ Email: gilmarab@iff.edu.br, silviac@iff.edu.br, liliana@cinted.ufrgs.br \\ Received July $5^{\text {th }}$, 2011; revised July 20 ${ }^{\text {th }}$, 2011; accepted July 26 $6^{\text {th }}, 2011$.
}

\begin{abstract}
According to the social-historical theory, interaction between individuals plays a major role in building the human being. It is through such interpersonal relationships that the individual's psychological development takes place. Therefore, in school education, interaction with teacher and with classmates is essential; in addition, their mediation along the educational process is an extremely relevant factor to achieve goals. Mediation also includes use of tools and signs in the social context, enabling the development of superior psychological processes. This research was carried out using the social-historical theory as theoretical background and considering that digital technologies enable adequate spaces to perform investigation activities. It was performed with a group of students Mathematics teachers and aimed at analyzing a learning situation about Triangle Similarity Cases using a Dynamic Geometry software program. The importance of mediation (tools, teacher, classmates) in knowledge building was evaluated by performing investigative activities aided by the software. Qualitative research, through case study, was chosen and three data collection techniques were used: participant observation, questionnaire and semi-structured interview. Research-related tasks were divided into three stages: preparation; development and analysis of collected data, relating them with the adopted theoretical background. Considering all that was observed and collected through questionnaires and interview, it is possible to state that mediation played an important role during software activities.
\end{abstract}

Keywords: Mediation, Social-Historical Theory, Mathematics, Dynamic Geometry

\section{Introduction}

Many studies, using varied epistemological approaches, have been developed with the aim of analyzing Mathematics learning in schools (D’Ambrósio, 2001; Moysés, 2007; Bueno-Ravel \& Gueudet, 2009). Different forms of approaching mathematical themes have been used (Artigue, 2002; Johnston-Wilder \& Pimm, 2004; Maschietto, 2008). In this sense, the role of interaction in knowledge building, ${ }^{1}$ either mathematical or not, has been stressed (Laplane, 2000; Preti, 2002; Moysés, 2007). Interaction between individuals plays a major role in human development (Vygotsky, 1978). It is through interpersonal relationships that the individual's psychological development takes place.

A particular type of interaction is crucial in this study: mediation. This is extremely relevant in the development of educational processes, and the role of a mediator, encouraging reflections through the help provided, is important for the student's autonomy and knowledge appropriation (Passerino et al., 2008). Mediation takes place in the Zone of Proximal Development (ZPD), understood as a joint action structure in any context in which there are participants with distinct levels of responsibility and competence, who work together toward

\footnotetext{
${ }^{1}$ Studies in the educational area have shown the potential of mediation for learning and subject autonomy. Results can be seen in Coll (1990); Wertsch (1998); Doise (1988), among others.
}

problem solving (Cole, 1986). Mediation also includes use of tools and signs in the social context, and the combination of such mediating resources enable the development of superior psychological processes (Vygotsky, 1978).

Two essential qualitative changes occur by using tools (and/or signs). One is that use of external marks will become internal mediation processes: this mechanism is called internalization process by Vygotsky (1978). The other change is that symbolic systems are developed (language is the basic symbolic system), which organize signs into complex and articulate structures (Oliveira, 1993). Both internalization process and use of symbolic systems are crucial to the development of superior mental processes and show the importance of social relationships between individuals in building psychological processes. From the importance of social relationships results the importance given to the role of teachers and classmates (teacher and classmate mediation) aiding the learning process.

Use of tools, associated with teacher and classmate mediation in investigative activities, may contribute to learning of Mathematics. Mathematical investigations involve concepts, procedures and representations, but the focus is on the conjecture-test-demonstration sequence (Ponte et al., 2005). These authors claim that, in Mathematics, "investigating is finding out relationships between known or unknown mathematical objects, trying to identify their respective properties" (Ponte et al. 2005: p. 13).

In mathematical investigations, digital technologies can be 
favorable resources. Such technologies highlight the role of graphic language, relativizing the importance of calculation and symbolic manipulation (Ponte et al., 2003). The graphic focus fosters reflections and critical analyses, enabling less mechaniccal procedures than those purely algebraic. Digital technologies are mediating tools that, whenever well used, can contribute to creation of ZPD. Use of these technologies, however, should be conscious and critical.

This paper describes a study performed with a group of undergraduate students in Mathematics at Instituto Federal de Educação, Ciência e Tecnologia Fluminense (IF Fluminense) Campos dos Goytacazes, RJ/Brazil. It aimed at verifying the importance of mediation (tools, teacher and classmates) in knowledge building at a situation of mathematical learning about Triangle Similarity Cases using a dynamic geometry software program. This article is structured in other five sections, in addition to this introduction. In section 2, two essential themes on which to base the research are briefly discussed: the social-historical theory and the importance of using digital technologies in the teaching and learning process. Section 3 presents the objectives and methodology of this study. Section 4 describes the activities performed and their objectives. Section 5 presents analysis and discussion of results in the light of the adopted theoretical background. Finally, Section 6 brings some considerations on the research and on obtained results.

\section{Theoretical Issues}

This section focuses on the social-historical theory, mainly considering the concepts of mediation, internalization and ZPD, required for the study described herein. Next, the issue of using digital technologies in the teaching and learning process is discussed, showing, according to the view of some authors, the advantages such technologies may bring to education and particularly to Mathematics, if properly used.

\section{Social-Historical Theory}

A key concept to understand the social-historical theory is mediation. Mediation is the intervention process of an intermediate element in a relationship, which is no longer direct and starts being mediated by this element (Vygotsky, 1978). As the Marxist theory conceives the tool mediating man's labor activity, Vygotsky (1978) conceives the notion of sign ${ }^{2}$ mediating thought. Sign acts as a tool of psychological activity similarly to the role of tool at work. However, Vygotsky (1978) stresses that this analogy does not imply identity between similar concepts and states that the fundamental difference between sign and tool consists of the different forms by which they guide human behavior. The tool's function is to serve as the conductor of human influence on the object of activity, it is externally oriented, it must lead to changes in objects. The sign, on the other hand, changes nothing in the object of a psychological operation. It is a means of internal activity aimed at mastering oneself; the sign is internally oriented (Vygotsky, 1978).

Human activity can only be understood if we consider that such tools and signs participate in it. This participation, which is not auxiliary but central to the development of activity as it

${ }^{2}$ Examples of signs are language, counting systems, mnemonic techniques, algebraic symbolic systems, among others (Moysés, 2007). acquires qualitatively different characteristics, is called mediation in the social-historical theory.

When signs are incorporated into the structure of cognitive processes, as an essential means of orientation and domain in psychic processes (Vygotsky, 1993) we are facing internalization. Therefore, internalization is the process through which an external operation is reconstructed and starts occurring internally (Vygotsky, 1978). Human beings, in their development process, no longer need external marks and start using internal signs (mental representations that replace objects in the real world). Internalized signs represent objects, events or situations.

In addition to mediation through tools and signs, there is human mediation (Kozulin, 2003). To Vygtosky (1978), the main function of intentional action of one subject over another in a child's development is based on the idea of mediation. Thus, education is seen as a social space for mediation in which tools, signs and people mediate the development process (Karpov, 2003). Mediated learning necessarily goes through active participation of an adult or more experienced partner that selects, modifies and interprets context conditions present in the learning process of another subject (less experienced) (Gindis, 2003). According to Vygotsky (1978), functions in a child's development occur in two different levels: first in the social level (between people, as interpsychological category) and then in the individual level (child's self, as intrapsychological category). This is equally valid for voluntary attention, logical memory and concept formation. In fact, all superior functions are originated from real relations between individuals. Although there are many forms of mediation, it has not yet been possible to identify a pattern for them because they are context-dependent (Kozulin, 2003).

Moysés (2007) clarifies that each psychic function that is internalized requires a mental restructuring as such function will interact with other existing functions in the child's mind. However, this is not about overlapped layers, but coordination between the new function and other existing functions.

As to the formal educational process, Moysés (2007), in his research, ${ }^{3}$ verified that mediation through different resources favors knowledge building by the student. A type of mediation often present at school is that developed by another subject, who creates learning situations in which tools and signs are intentionally introduced in an action (Baquero 1996). Such teacher mediation acts directly on each student's ZPD. ZPD is the distance between the actual developmental level, as determined by independent problem solving, and the level of potential development, as determined through problem solving under adult guidance or in collaboration with more capable peers (Vygotsky, 1978). The author states that a child's state of mental development can only be identified if the level of actual development and ZPD are revealed.

In school education, the teacher is this more experienced subject that through guide-questions, examples and demonstrations, performs interventions that can help the student do a task (Moysés, 2007). It should be stressed that interaction between students also causes interventions in their development. In

\footnotetext{
${ }^{3}$ Moysés (2007) reports a study in the area of Mathematics including $6^{\text {th }}$-grade students from a public school, based on the theory proposed by Vygotsky and his followers. The researcher investigated possible applications of this theory for the educational process being studied.
} 
groups of students generally heterogeneous as to previous knowledge, a more advanced student may contribute to the development of others (Oliveira, 1993).

Moysés (2007) stresses that, although learning through demonstrations presupposes imitation, it should not be seen as a copy, but as something involving constructive experimenting. Such experimentation enables concept formation.

Concept formation was also studied by Vygotsky (1986), who classified them as spontaneous and scientific and analyzed how they interacted. Spontaneous concepts are those in which the child learns in her daily life, originating from contact with objects, facts, phenomena, among others, of which she is frequently unaware. Scientific concepts are systemized, hierarchized and intentionally transmitted, generally following a methodology. These are essentially the concepts learnt at school.

Development of scientific concepts presupposes a conscious and consented relation between knowledge subject and object. Their formation is a mental operation that demands attention on the issue, deriving essential aspects from it and inhibiting secondary concepts and aiming at wider generalizations through synthesis (Vygotsky, 1986). There is then a process of analysis and synthesis, abstraction and inhibition of given characteristics; in addition, there is movement of thought within the pyramid of concepts, constantly alternating from the particular to the general, and vice-versa (Vygotsky, 1986).

Several topics dealt with in this section were observed in the research and are commented in the analysis and discussion of results (Section 5).

\section{Use of Digital Technologies in Mathematical Learning}

Digital technologies enable adequate spaces to perform investigation activities, in which the teacher observes, guides, suggests questions and reflections, encourages socialization of ideas and fosters critical analysis of results.

However, it should be highlighted that such technologies are favorable tools to new educational practices, but alone they are not the solution for educational problems. As supported by Valentine and Soares (2005), change is not in technology itself, but in new relations it stimulates. In this sense, it is crucial that: 1) there is a restructuring of the student's and teacher's role; 2) the focus is on learning, not on teaching; 3 ) the teacher provides interventions and guidance based on social and cognitive observations of students; 4) relations emerging from interaction are considered, enabling learning to learn and development of competences (Valentine \& Soares, 2005).

In Mathematical learning, these technologies can collaborate to content understanding since they facilitate things through use of computational ability, graphic visualization, discovery and confirmation of properties, possibility to run experiments with data collection and problem modeling, speculations, among others (Baldin, 2002). Particularly, use of online resources and specificity of some of them should be the attention focus in studies on Mathematical Education (Bueno-Ravel \& Gueudet, 2009). According to the authors, this requires theoretical evolution that enables capturing the phenomena associated with the teaching and learning process.

Educational software programs, among other digital technologies, are tools that can collaborate to improvement of learning environment quality. These allow exploration, visualization and experimentation of varied situations, of which some are virtually impossible to be performed without their aid.

Compass and Ruler, ${ }^{4}$ a program used in this research, is a free software program that has a quite open proposal, favoring knowledge building. Its purpose is to work with dynamic geometry, that is, its function is to allow creation of geometric constructions that can be changed by moving one of the basic points and enabling preservation of original properties. This program has no specific content to be studied, but tools for geometric constructions to be used, depending on the intended objective. Some positive points of Compass and Ruler: 1) it is easy to use; 2) it has a pleasant, didactic interface; 3 ) enables simple to quite complex geometric constructions, depending on the user's ability and need; 4) it favors knowledge building; 5) it stimulates creativity and questioning; 6) it enables interactivity; 7) it offers resources that make Internet constructions (applets) possible.

Computer programs focused on dynamic geometry are very useful resources to study Geometry since they allow movement of constructions, favoring visualization of a varied number of situations that collaborate to understanding of the theme under study. In addition, such resources enable relating empirical explorations and formal tests, and can be used to highlight a deductive argument in demonstrations (Guven, 2008).

Fainguelernt (1999) states that studying Geometry is extremely relevant for the development of spatial thinking. According to the author, thinking activated by visualization involves intuition, perception and representation, which are essential skills for world reading and not to have a distorted view of Mathematics.

Conviction of the authors of this study regarding the importance of digital technologies for Mathematical Education, coherent with the ideas of the above-mentioned authors, is based on research and experience in the classroom. This favorable position in relation to digital technologies guided this entire research study.

\section{Research Configuration: Objectives and Methodological Aspects}

The general objective of this study was to verify the importance of mediation by teacher, classmates and tools in knowledge building at a situation of mathematical learning about Triangle Similarity using the Compass and Ruler program. Secondary to the above, the following objectives were also included: 1) identify and analyze forms of teacher mediation (individual and in group); 2) verify whether and how collaboration between classmates in group activities took place; 3) identify forms of software use in problem solving; 4) verify whether the activity performed using the software collaborated to the understanding of involved concepts.

The sample included a group of students of Geometry II, Mathematics Teacher Education Program, IF Fluminense Campus Campos-Centro (RJ/Brasil) $-2^{\text {nd }}$ semester of 2008. This course is taught by one of the authors and the group was composed by 15 students; these aspects facilitated real-life observation.

It was a qualitative research through case study. Preference for a qualitative study was based on some of its basic charac-

${ }^{4}$ Created by René Grothmann (professor of the Catholic University of Eichstätt, Germany), available at

<http://mathsrv.ku-eichstaett.de/MGF/homes/grothmann/zirkel/>. 
teristics that, according to Bogdan and Biklen (1998), are having natural environment as a direct source of data and the researcher as its main instrument; collected data are predominantly descriptive; higher concern about the process than about the product.

The advantage of using a case study lies on the possibility of having deeper knowledge as it has no restrictions of comparing the case study with other cases. Furthermore, in this type of study, researchers have more time to adapt their tools, change their approach to explore unpredictable elements, need some details and create an understanding of the case that takes all that into consideration (Laville \& Dionne, 1997).

Data collection techniques were basically participant observation, questionnaire and semistructured interview. In participant observation the researcher is integrated and takes part in group activities. A reflexive position toward observed subjects is needed, making notes, recording and collecting data through tools considered to be convenient during the investigation. There is no restriction to the investigation neither an a priori analysis structure; therefore, it is possible to have a wider view of the situation and consider many aspects, without isolating them from each other. However, it should be stressed that, during participant observation it is not always possible to make notes during the process, which demands discipline and good memory by the observer (Laville \& Dionne, 1997). Although this technique has some inconveniences, such as those mentioned above, it is considered that its advantage in terms of context understanding makes it an adequate technique for this research. As a complement to participant observation, questionnaires as well as a semi-structured interview as an attempt to obtain possible information that was missed in participant observation, or even to confirm what was observed.

The questionnaire was used because, among other advantages, it allows anonymity and does not expose subjects to the influence of the interviewers' opinions and personal aspects. However, this technique prevents knowing the circumstances in which it was completed (Gil, 1999), which explains use of the interview. Using more than one data collection technique enables a better triangulation of sources and methods (Yin, 2003).

Questionnaires were completed by students Mathematics teachers in the classroom, in the presence of the researchers during study stages. Efforts were made to ensure all questions were clear, so that there were no misunderstandings.

The interview is wider than the questionnaire in terms of organization. The interviewer, who is not restricted by a document, can better explain some questions throughout the interview or rephrase them to favor understanding (Laville \& Dionne, 1997). This study used a semistructured interview, which consists of a series of open questions, made verbally according to a predicted order, but with a possibility of inserting new questions depending on the interviewer's needs (Laville \& Dionne, 1997). The aim was to collect data that might not have been asked by the questionnaires neither perceived during observation.

After choosing the methodology to be used, three study stages were defined:

- Preparation

- planning of the learning situation, describing actions to be developed and strategies to be used;

- creation of exercises to be performed without using the software, with the aim to check whether students already knew the theme to be studied;

- creation of pedagogical activities about Triangle Similarity using the Compass and Ruler program;

- creation of exercises to be performed without using the software, with the aim to check understanding of the theme to be studied;

- creation of questionnaires and questions for the semistructured interview.

- Development: application of activities and questionnaires, observation of the entire process, register of observations and interview.

- Analysis of collected data, relating them with the adopted theoretical background.

Research results are presented next.

\section{Study Development}

This section reports study development. Activities performed and their objectives are described, but there is no deep analysis on the varied aspects under observation as this will be discussed in Section 5.

The case study was performed during three meetings (once a week), each lasting 2.5 hours. There were 15 students in the first meeting; 10 in the second, and 14 in the third. The study purpose was presented to the students in the beginning of the first meeting, when the importance of their committed participation was also stressed.

Initially, exercises were proposed to diagnose the knowledge students already had on Triangle Similarity. These exercises were collected by the researchers ${ }^{5}$ and analyzed between the first and the second meeting.

Next, three activities were proposed using the Compass and Ruler software. ${ }^{6}$ These are activities of geometrical construction that aim at enabling establishment of conjectures about triangle similarity cases. Until the end of the first meeting, most students had finished activity 1 of this set of activities. They were asked not to solve the other activities at home, but in the following meeting.

In the second meeting, the students did the activities using the software. Established conjectures and developed constructions were discussed and presented to the group. Conjectures, recorded in the activity sheet, and files containing the answers, were collected and analyzed between the second and the third meeting.

Also in the second meeting, the students completed a questionnaire relative to the activities solved by using the software, as an attempt to collect data on: 1) the role of teacher and classmate as mediators of the learning situation; 2) the importance of activities for learning the theme; 3 ) the importance of using the software as a learning tool.

In the third meeting, researchers formally demonstrated the first case of triangle similarity. Demonstration of the second case was only commented. Conjectures raised and discussed in the previous meeting were then generalized.

${ }^{5}$ It should be stressed that the researchers also played the role of teachers throughout the study, that is, they were not only observing the situation, but also acting as mediators.

${ }^{6}$ All students had already used the software in other learning situations; therefore, activities to learn its features were not necessary. 
Initial exercises were handed back to the students participating in the study for analysis and discussion of what was initially done. A reflection on initial resolutions was proposed in the light of what was studied aided by the software and discussed in group. Exercises 2 and 3 of the initial test were then remade. Constructions made in the software were also commented based on formalization of the studied theme.

Next, students, as a group, solved a list of contextualized problems without aid from the software. They were collected for further analysis. Students also completed a second questionnaire, which aimed at collecting data on: 1) the role of teacher and classmate as mediators of the learning situation; 2) the influence of software activities on exercise solving without the software; 3) the importance of using geometrical pictures (triangles) as a learning tool.

It should be stressed that, in all described stages, attitudes and comments considered significant to achieve the study's objective were observed and recorded. Based on the analysis of everything that was developed, a semi-structured interview was performed with five students (selected after analysis of responses and attitudes), aiming to obtain further information.

This study design was based on the statement by Cole and Scribner (1978: p. 13):

"To serve as effective means to study "the course of a process development," an experiment must provide as many opportunities as possible to have the experimental subject engaged in the most varied activities that can be observed and not only rigidly controlled. An effectively used technique by Vygotsky with this purpose was introducing obstacles or difficulties in the task to break routine problem-solving methods. [...] Another method was providing alternative paths for problem solving, including many types of materials (called "external auxiliaries" by Vygotsky), which might be used in different ways to meet the test's demands. [...] A third technique was confronting the child with a task that exceeded her knowledge and abilities, as an attempt to evidence the rudimentary beginning of new skills."

The three techniques suggested in the above excerpt were applied to the study case described in this research. Students participated in varied activities, with distinct objectives and methodologies (activities of diagnosis, knowledge building, socialization of conjectures and application). In addition, they were prepared considering different levels of difficulty. Software features enabled different paths in activity solving, which enriched the process. Although activities did not exceed much of students' ability, they approached new contents for most of them, differently than those traditionally used in classroom. This fact allowed observation of students' first steps in terms of theme learning.

\section{Analysis and Discussion of Results}

Five subsections were organized for analysis and discussion of results. They correspond to the sequence stages of the study.

\section{Resolution of Initial Exercises}

As described in Section 4, in the beginning of the first meeting three exercises were proposed with the aim of diagnosing the knowledge already possessed by students about Triangle Similarity, before performing the activities that would be pro- posed.

Since one of the authors teaches this discipline, it was known that by the time the study was carried out the theme Triangle Similarity Cases had not been studied in the course. However, such fact was no guarantee that it had not been studied in another context. Thus, this stage was important as it allowed verifying whether or not the theme was new to students. This is in accordance with Vygotsky (1978), when he stated it is important to identify the level of actual development (starting point) to act in ZPD.

Students were told that during exercise solving they should base their responses. Furthermore, they knew they could leave some or even all exercises unanswered, as long as they provided a justification for it.

All students tried to individually solve the exercises using the definition of similarity (which had already been studied in the course), but it was affirmed that triangles were similar. This fact implied verification of such condition (similarity cases), which was only performed by one participant. ${ }^{7}$ It is important to stress that, although it was an individual activity, students exchanged ideas during problem solving.

Some students left exercises unanswered or incomplete, but in the analysis it was possible to perceive such fact resulted from the difficulty in identifying homologous sides, and not because they had no guarantee of similarity. Attempt of solving the exercises "automatically" is something common in Mathematics classes, as a consequence of traditional practices.

It is important to highlight that the imitation view differs from that of Vygotsky (1978; 1986), for whom imitation is not a copy of a model, but the reconstruction of what is observed in the other's action. Imitative activity is not a mechanical process, but an aid to perform actions beyond one's ability, which contributes to development.

In summary, except for one student, all others were unaware or could not remember the theme being addressed in this study - Triangle Similarity Cases. They only knew the definition of similar triangles.

In the first research stage, it was possible to perceive the importance of figures in problem solving. Such fact was perceived by observing that students moved the exercise sheet or reproduced one of the triangles on the paper, drawing it in the same position as the other, which was expected by the researchers based on previous experience. In exercise three, for example, similar triangles were in different positions, so one student asked help for the researchers to draw the lower triangle in the same position as the larger one. This fact portrays the difficulty in identifying homologous sides and the importance of teacher intervention in the development of activities. According to the group's teacher, when triangle similarity was defined, students were told they did not have to draw triangles in the same position. The teacher also reported it was stressed that it would be enough to identify respectively congruent angles so that homologous sides could be identified. In summary, this idea was not internalized; in addition, this fact showed that even adults need mediation through tools (triangle drawing) to think and solve. According to Vygotsky (1978), use of mediating tools radically reorganizes superior psychological functions, such as

${ }^{7}$ During resolution of exercises, this student asked if he could use similarity cases to justify his resolution. He also claimed to have previously studied triangle similarity cases in high school. This means that the exercise objective was achieved. 
memory and attention. Other students also called the researchers to explain they "turned" the triangles. Six students did not solve the third activity. Although there was enough time, they were not able to do it neither justified lack of solving.

When the first student finished and handed in the exercise sheet, another student immediately called him to ask for help. This student helped solving some activities by showing, through software recourse, the sequence of constructions he used. This fact reinforces the importance of imitation, considered in a wide sense, as previously stressed,

\section{Problem Solving Aided by the Compass and Ruler Software}

In the second stage three activities were proposed to be solved using the Compass and Ruler Software. These are activities of geometrical construction that aim at enabling establishment of conjectures about triangle similarity cases, as described in Section 4. Observation of attitudes and questions during classes, and analysis of problem solving allowed recording important situations to learn the theme, as described next.

Proposed activities are not traditional, as commonly found in didactical books. As it can be seen in Figure 1, they are investigative activities. According to Ponte et al. (2005), investigating is a powerful form of building knowledge.

Students had much difficulty in performing what was requested in the first activity because they misinterpreted the headings, displaying a certain degree of functional illiteracy ${ }^{8}$ in problem solving. Triangles were built using the definition, and not the condition imposed in the heading. This problem was mitigated in activity 2, although it was still present. In addition, in activity 1 students had difficulty transposing angles, although they had already performed such action in another course discipline, but without using any software program. Therefore, there was the need of mediation by the researchers, who used questions to remind students of the required sequence for angle transposition. Furthermore, some students saw the construction in their classmates' monitor to try to discover how it had been done. This attitude, as described earlier, helps performing actions beyond one's own ability, which contributes to development. Teacher's mediation and use of software were essential to achieve the objective in activity 1.

Figure 2 presents the requested construction in activity 1. Gray lines indicate the drawing needed for construction, which can be hided using software features. All drawings are shown to analyze constructions. Another resource used was "Repeat construction," which enables visualization of the sequence performed by the student. After analysis of constructions using the features above, it was possible to observe that, except for one student, all of them used angle transposition. The student that did not use this path applied parallel lines, which is a more efficient form than that used by the other students. This student had already studied the theme, and therefore was at a more advanced stage than the others. According to Vygotsky (1978), each theme studied at school has a specific relation with student development, and such relation varies as students move from one stage to another.

\footnotetext{
${ }^{8}$ Functional illiterate is the person that, even knowing how to read and write, has not reading, writing and calculating skills required to foster their personal and professional development.
}

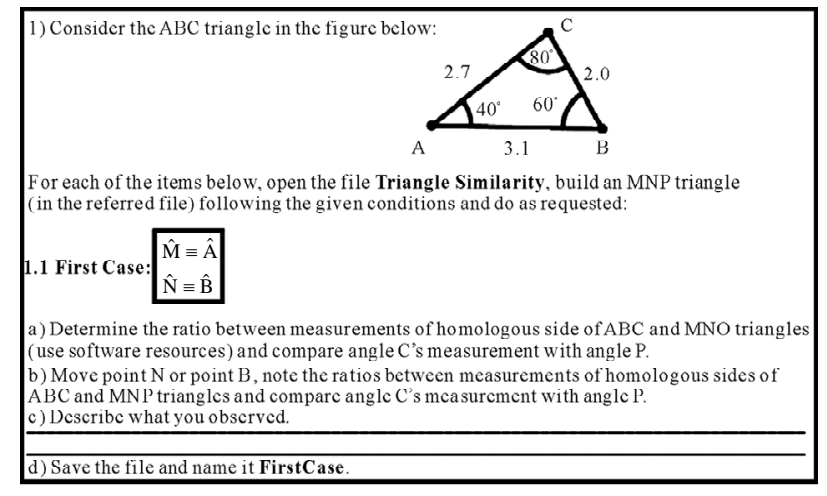

Figure 1.

Activity 1-Compass and ruler software.

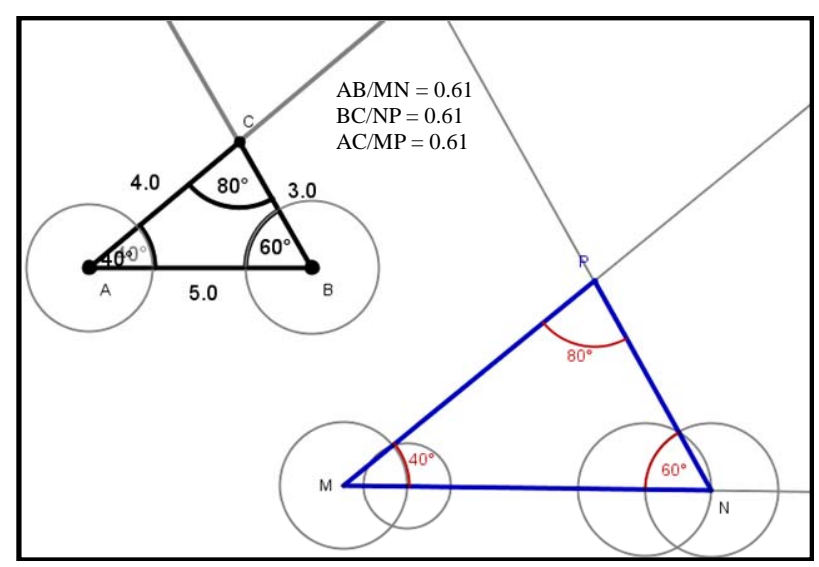

Figure 2.

Construction-Activity 1.

By the end of the first meeting, only one student had concluded the second activity. The second meeting was then started to continue problem solving. In activity 2 (Figure 3) it was necessary to construct proportional segments. Students proved to know what the process was (which was confirmed by oral description). However, since the construction required many circumferences, some students drew wrong segments. By moving the construction using software features, some students realized there was something wrong, since they had understood the activity objective and knew that, to have similar triangles, angles should be congruent to those of the given triangle, which did not occur. At that moment, some students did the construction again, others asked help for a classmate and others requested help for the researchers. When solving activity 2, two students said they found it very difficult to do the construction. The students claimed to have done it three times, but they did not give up, felt challenged and persisted until obtaining the correct construction (in the fourth attempt). This was the activity students had more difficulty to perform. Such fact is attributed to the drawing of proportional segments that would require construction of several circumferences, as shown in Figure 3.

According to Vygotsky (1978), a crucial aspect of learning is that it creates ZPD, as explained in Section 2. To have an effecttive learning, many internal development processes should be awakened. In addition, this author states that it occurs when the 


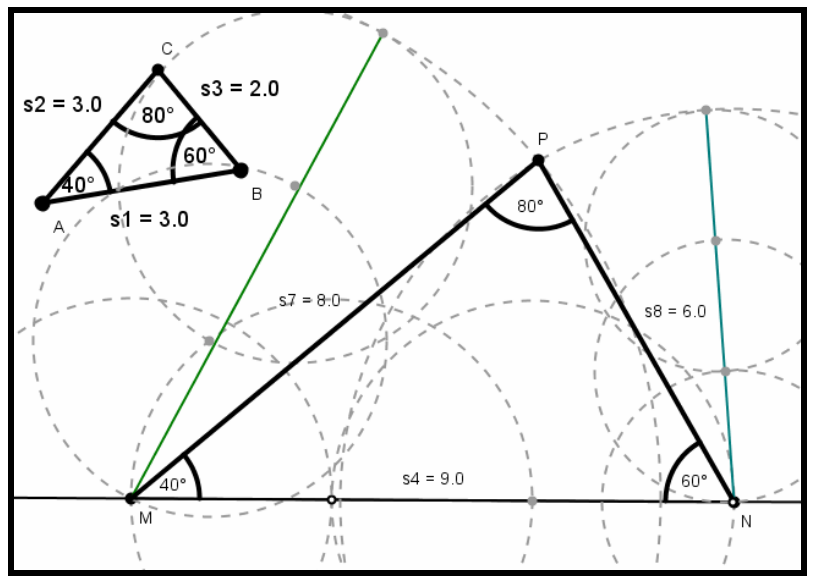

Figure 3.

Construction - Activity 2.

student interacts with people in his environment and in cooperation with his partners. The attitude of both students and also of the other students indicate that the activities enabled creation of ZPD; in order to reach their objectives, it was necessary to develop internal processes, as well as an interaction with researchers and with classmates.

Activity 3 was solved without any difficulty, since it involved concepts used in the previous activities. Such fact suggests that activities 1 and 2 were solved consciously, as they had a positive influence on the following activity. As in both previous activities, although each student was using a computer, they discussed the entire process of problem solving. This confirms that development of superior functions derives from actual relations between individuals (Vygotsky, 1978). According to this author, shared activity is important for cognitive development as it allows living in the external plane what will be later internalized.

By the end of each activity, students generally called the researchers to show their constructions. Questions such as "Is it correct?" were answered with other questions, making them debugging what they had done and identify the error in case it occurred. Such attitude was more frequent during the first two activities. In the third activity, most students reflected a little more on what they were doing (students identified their errors by themselves or aided by the classmate sitting next to them).

\section{Discussion and Formalization of Conjectures Established in Activities}

The stage of discussion and formalization of established conjectures was started after students concluded the activities. The researchers coordinated this stage by requesting students to orally describe construction and answer to item c of each activity. This item requested the student to write what was observed based on the construction and on its investigation. When a student described a different path from other students, he should socialize the procedure and present his construction to the group.

In activity 1, all students orally answered that if two triangles have two orderly congruent angles, then they are similar. One student described the steps of her construction using the software feature "Repeat construction," showing that she used the angle transposition process to construct congruent angles. Among other students, only one claimed to have used parallel lines to construct congruent angles, but at the end he established the same conjecture. When this activity was developed, the resolution process used by this student was not predicted. This fact is warned by Borba and Penteado (2005), who stressed that when using digital technological resources, a teacher should be able to deal with unpredictable situations. It is worth stressing that there was yet another way (using the feature "Fixed amplitude angle" to construct congruent angles).

In activity 2, only one student associated the condition imposed in the activity with the definition of triangle similarity; all others said that only sides are proportional and that angles are congruent, which did not prevent reaching the activity objective as responses are equivalent. One student described the steps of construction using the software feature "Repeat construction." At that moment, this student said his construction was not the first he had done; in his opinion, his first attempt was too complex, so he decided to do the activity again to simplify it. This statement describes the path followed to solve the activity, stressing how the student thought. Such fact highlights the importance of discussing and presenting results in investigation activities, as supported by Ponte et al. (2005). After all, without this moment the student would not have the opportunity to express himself, and consequently process analysis would be incomplete. All other students claimed to have used the same construction process.

In activity 3, analysis of oral responses showed that students realized imposed conditions for construction ensured triangle similarity. This fact is attributed to the comments made in activities 1 and 2. This reinforces the idea that, when performing a given activity, representations are being formed and their richness allows going beyond a mere description and/or memorization of the theme being studied, as supported by Moysés (2007). Since the construction process in activity 3 was analogous to that of activities 1 and 2, description of constructions was not requested. Analysis was performed based on construction files collected by the researchers.

After discussion was over, one of the researchers asked if all three exercises proposed before the software activity could be solved without knowing about similarity cases. Students were also asked about what led them to construct proportions using measurements of triangle sides. Students did not give immediate responses; one student said it was due to Thales' theorem. The researcher then explained that this theorem is not sufficient to support resolution of the activity. Statements showed that students (except for one, who was already aware of the theme) constructed the proportion merely because they were studying similar triangles, which have proportional sides. That is, for most students any two triangles were similar. However, these students reported that, after solving the activities using the software, they realized that the first exercises were solved without any background. The second meeting eliminated these questions.

The third and last meeting started with a review of the stages performed in previous meetings. Next, one of the researchers demonstrated the first case of similarity on the board. Demonstration of the second case, as it was similar to the first, was conducted by the students, who listed the demonstration steps. Demonstration of the third case was given as homework. 
After similarity cases were formalized, the researchers commented on constructions performed in the software (whose files were collected and analyzed between the second and the third meeting), based on the analysis and considering the demonstrations. It was not possible through file analysis to understand one student's construction, so she was asked to explain the procedure and its stages. This is another situation that highlights the importance of discussing and presenting results in investigation activities.

Next, students were asked to do exercises 2 and 3 again. Exercise 2 was solved along with the researchers (in a dialogical manner), and students had to do exercise 3 by themselves. Similarity cases were easily identified. Response accuracy was much higher than in the first resolution (diagnostic stage). Positive results are attributed to the sequence of activities, which included use of the software (tool), intervention by mediators, classmate collaboration, discussions and socialization of procedures used in previous stages.

\section{Resolution of Final Exercises}

According to Vygotsky (1978), the level of actual development is the level of an individual's mental functions that were established as a result of completed development cycles. With the aim of analyzing the level of actual development of participants in relation to the theme under investigation, six exercises were proposed about what was conjectured in the softwareaided activities and further demonstrated. Figure 4 shows three of these exercises.

At this study stage, students were distributed into small groups, chosen by them. However, the students that missed the second meeting (four students) were grouped in such way to ensure there were students who attended all meetings. Exercises were problems that required domain of the content being studied to be solved. Students were asked to make a full register of exercise solving to enrich the analysis. During exercise solving, students were quite interested and more rigorous in establishing the resolution (by providing a background for each resolution stage). They constantly requested presence of the researchers to check their answers.

It is important to stress that there was a dialogue between group members and between different groups to answer questions and check their responses. Students compared resolutions

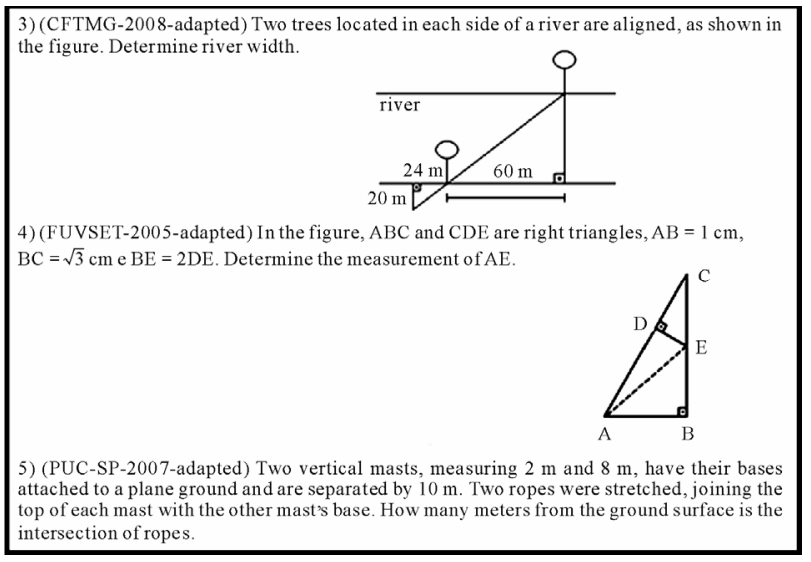

Figure 4.

Final exercises. and sometimes concluded that although different, paths were correct. One student's statement reflects what was described, as well as shows that the theme was understood: "I went from the small to the large triangle and you did the opposite, but the result is the same." In this stage it was possible to experience situations in which learning of concepts had its origins in social practices (Vygotsky, 1978).

When one of the students, who had missed the second meeting, was asked if she was being able to solve the exercises, she answered that "I can manage it with your support and helped by my classmates." This statement reinforces the idea that in groups of students, generally heterogeneous as to previous knowledge, more advanced students may contribute to the development of others (Oliveira, 1993).

In exercise 4, as well as in others, students easily identified the similarity case, but the difficulty in calculating one of the sides was remarkable. Students had to use the Pythagorean theorem, which had already been used in other exercises, but most of them could not identify such need. Since this difficulty remained for a certain time, one of the researchers intervened making questions that gave the idea of using that theorem. As stated by Moysés (2007), guide questions, examples and demonstrations are important intervention forms that can help students perform an activity.

The two last exercises had no figures, a situation that had been previously planned. Importance of figures for problem solving was manifested in students' statements. During the activity, two students of different groups said the following: "My problem is when there is no figure." "Is my figure is correct?" These statements were not addressed to anyone in particular, which in the social-historical theory is called "interior discourse," which is a discourse focused on thought, addressed to the subject himself, with the aim of helping the individual in his psychological operations. Language as a tool of thinking (Oliveira, 1993).

The importance of figures is stressed by Moysés (2007: p. 75): “[...] by establishing a relation between a given situation in- volving calculation and a representation-either formed by different or richer mental images, or through diagrams, schemes, more evocative verbal descriptions, gestures, simulationscontextualized thinking favors articulation of variables and contributed to the success of the mathematical problem solving process".

In exercise 5, the difficulty of not having a figure was overcome by exchange of ideas between group members; therefore, identification of two pairs of similar triangles was correctly performed based on similarity cases. This fact is attributed to the set of activities performed throughout the meetings. To end this exercise, students had to construct two proportions and later solve a system. Some groups had difficulty, so one of the researchers organized the conclusion on the board through an active participation of students. This exercise was considered very difficult, but all groups came close to the final answer before the intervention.

In exercise 6, two students had difficulty interpreting "inscribed circumference.” One student drew a circumscribed circumference and another drew a tangent in only two sides. Another problem was the drawing of a right angle in the smaller triangle (from the center to the tangential point), which generated errors in identification of homologous sides. The 
situations above influenced exercise solving. For this reason, the researchers provided the required support to the groups, enabling them to successfully solve the activity. Changing a person's performance through interference of another is stressed in the social-historical theory (Oliveira, 1993; Baquero, 1996), as it represents a moment of development (students cannot do it by themselves). In addition, such change is a result of social interaction in the process of building superior psychological functions, an important aspect of the social-historical theory (Oliveira, 1993).

Students actively participated in exercise solving. Group interaction was very strong, and the richness of interpersonal exchanges contributed to problem solving.

It was possible to perceive that mathematical investigations involve concept, procedures and representations, in addition to the importance of the conjecture-test-demonstration sequence in learning (Ponte et al., 2005), as described in the introduction.

\section{Analysis of Questionnaires and Interview}

Students had to complete two questionnaires during the study. The first was completed soon after solving activities using the Compass and Ruler software, and the second was completed by the end of the last meeting, after solving the exercises in group. The students that missed the second meeting did not answer all questions of the second questionnaire.

To facilitate analysis of questionnaire answers, students were numbered (Student 1, Student 2, and so on), and the numbers were maintained in both analysis.

\section{Analysis of Questionnaire 1}

Ten students completed the first questionnaire. When asked about the importance of the teacher as mediator in problem solving using the software, $80 \%$ of the students considered it "very important" and the remaining $20 \%$ found it "important." The comments made by two students that considered the teacher's mediation as "very important" stand out. They stress the role of teachers as advisers, enabling development of activity and knowledge building.

The teacher's participation was crucial for problem solving, because when there were construction mistakes she helped me find where the error was so I could go on with the construction (student 4).

The teacher is essential for knowledge building. It was not different here. She served as a bridge so we could reach the proposed objectives (student 9 ).

The statements above show that students realized the importance of mediation that is not directive and authoritative, as supported by the social-historical theory (Oliveira, 1993).

As to importance of classmates for problem solving using the software, $50 \%$ of the students considered it "important" and the remaining found it "very important." Analysis of statements showed the importance of interaction in the learning process, as stressed by the social-historical theory. Two comments considered significant for the context of this study should be stressed:

My classmates also helped a lot in the construction, because together we could exchange information and realize where and why we were making a mistake (student 4).

Interaction between students to exchange ideas is important for a better development of the student (student 9).

When asked about the level of the activities solved using the software, most students (60\%) considered it "moderate" and the remaining classified it as "difficult.” These rates are attributed to the investigative nature of the activities. Although the theme is simple (it is part of the curriculum in elementary and high school), students are not generally used to solving investigative activities. Some justifications stand out (the first refers to a student that considered it "hard," and the second is from a student that considered it "moderate").

Solving it was difficult because we needed a lot of help from classmates and from the teacher. Without such help, I would take a long time to finish the exercise (student 4).

The activities were developed to make us think, do and understand the class's objective (student 8).

Although activities were not considered easy, it was a satisfaction to perceive that software (tool) use to learn the theme was considered "very important" by $90 \%$ of the students and "important" for the remaining $10 \%$. These rates reinforce the importance of using tools during an individual's development, in agreement with the social-historical theory. In addition, the statements below indicate that students are aware of the advantages of using the Compass and Ruler (and similar) software to study Geometry. This is an important fact, given that they are students Mathematics teachers.

Because the student has the opportunity to find out the content through experiences that confirm the theoretical part of the content (student 3).

The software gave us a better perception of the activity conclusions. Without it, I think it would have been very difficult to perceive them. Moreover, it makes the class more dynamic and interesting (student 4).

Using the software we can, for example, move points and see that cases are valid for all other triangles, meeting the same conditions (student 6).

Widening the focus, the following question was about the importance of using the software in Mathematics learning in general. All students considered such use as "important.” Their statements demonstrate that students are aware of the possibilities generated by digital technologies: computational ability, graphic visualization, discovery and confirmation of properties, possibility to run experiments with data collection and problem modeling, speculations, among others, as supported by Baldin (2002), described in second section.

The software is a tool to help students understand some subjects they have difficulty visualizing (student 1 ).

Because students interact with the content, making learning more pleasant (student 3).

When students do and observe what they are doing, they have a better understanding and learn the theory (student 5).

As to discussion and formalization of activities, $70 \%$ of students considered it "very important," while the remaining found it "important." Analysis of comments shows the importance of interaction and idea exchange enabled by such actions.

Discussion is a way of aggregating new knowledge through your classmates (student 1 ).

By exchanging ideas people learn more and better (student 5).

These discussions show many forms of solving the same question (student 9).

\section{Analysis of Questionnaire 2}

After resolution of final exercises (without using the software), 14 students completed the second questionnaire. 
Most students reported having little difficulty solving the final exercises (Chart 1), which can be considered a quite satisfactory result. Three students did not answer this question because they missed one of the meetings. It is important to stress that students highlighted the importance of software activities to solve the final exercises, which reinforces the value of this tool in learning.

After the software activity it was easy to visualize similarity cases (student 1).

By constructing similarity cases in the software it was easier to remember what was constructed and associate it with the activities (student 6).

With the support of the software and studying similarity cases, it was easier to solve the exercises (student 8).

Also in the resolution of final exercises, most students considered teacher's and classmate's mediation as "very important" and "important." This result is similar to that obtained in data tabulation of the previous questionnaire. It is curious that, in the resolution of final exercises, classmate's mediation was considered "very important" by a higher number of students than teacher's mediation (as opposed to software activities). This is attributed to the fact that the exercises were solved in groups and to the activities previously performed. Without being requested, one student, when commenting on question 2, compared the teacher's mediation in both learning situations:

The teacher's mediation was important, but the number of times we needed her support was much lower than that of the previous activity (student 4 ).

With regard to classmate's mediation, some statements showing the importance of exchanging information during exercise solving stand out (the word exchange was present in five out of 14 comments):

Students' collaboration was very important because through them we could have a better visualization of what was right or wrong. Through information exchange we got to the result more easily (student 2).

It is of great help to develop thinking, and information exchange accelerates the development of questions (student 9).

The fourth question (open) asked whether, when solving the exercises after software activities, any association had been

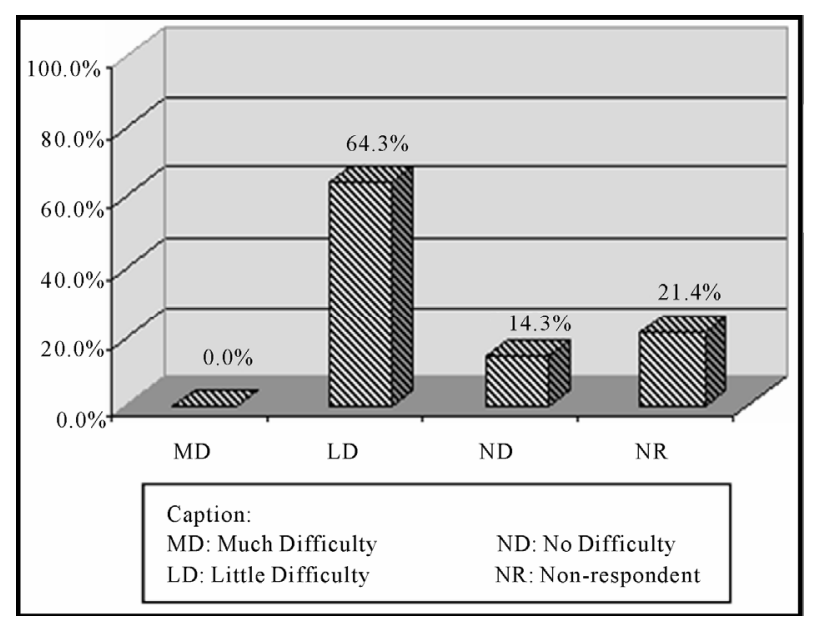

Chart 1.

Resolution of final exercises. made with the activities solved with the support of the software. Four students did not answer because they missed one of the meetings. All others answered affirmatively, stressing the importance of visualization enabled by the software, which influenced resolution of final exercises.

Only two students answered negatively to the question on having more difficulty solving the exercises that had no figure (tool); their justification is that they can easily represent the figure based on the heading information. These students are at a more advanced developmental level because they have already internalized the theme being studied. The need of figures was justified in the students' comments, of which the following stand out:

Yes, because it is easier to visualize the drawing, and sometimes we make mistakes because the drawing is incorrect (student 11).

Yes, because we are never sure about the drawing, and a wrong drawing leads to a misunderstanding of the exercise (student 12).

Yes, when you have ready figures it is easier to visualize triangle similarities (student 13).

\section{Interview Analysis}

In addition to questionnaires, five students were interviewed. As mentioned earlier, a semi-structured interview was chosen because it allows insertion of new questions according to the interviewer's need.

In general, it was possible to perceive that all students consider mediation by another person as something important in the teaching and learning process, either a teacher or a classmate. However, there is a certain preference for the mediation of a classmate. Of the five interviewees, only one preferred a teacher's mediation, claiming he has more knowledge on the subject and, therefore, his guidance and questions lead to a correct solution more objectively; three said they feel more comfortable with a classmate and ask help to the teacher only when they still have a question; one claimed he has no preference, but stressed that it depends on the teacher (he said some teachers are not open to questions).

They all considered that the activities performed with the Compass and Ruler software enabled occurrence of ZPD. One of the interviewees stated there were activities she could only do if helped by someone (a classmate or a researcher), but this made her learn, because nobody did it for her (she emphasized that, although helped, she did the activities by herself). Her statement is very interesting since it is obvious she is aware that doing an activity supported by someone is different from someone doing it for her, and here lies the essence of ZPD.

A comment by the first interviewee led to the formulation of a new question. This student said she really needs to visualize the figure when solving the type of question proposed in the study. Figures are essential to her, but she stressed they should be included in the question since she usually makes a mistake when drawing them according to the heading information. After this comment, all the other interviewees were asked about the importance of the figure and whether they find it difficult to draw it based on the information given. All the others affirmed the figure is important for problem solving, but they complemented by saying that, even without the figure, they can mentally visualize it based on the information given and then re- 
produce it on paper. The first interviewee is in an internalizetion process that differs from the others. She is also very dependent on the external mediation of figures as tools; in fact, she has not internalized them as signs.

In general, the data collected in questionnaires and interview showed the importance of using tools associated with investigative activities as well as of teacher's and classmate's mediation in resolution of activities.

\section{Final Considerations}

This section reviews some important issues about the study. Although the entire process has already been detailed in previous sections, an important aspect should be stressed: acknowledgment of the importance of social-historical theory for the teaching and learning process of Mathematics. Such acknowledgment originated from the perception, in practice, of coherence between theoretical background and students' actions and reactions.

Throughout the study, shared activity was emphasized. Its presence sometimes made creation of ZPD evident. Through the mediation of classmates and/or researchers, many students were able to perform tasks they could not do by themselves, clearly showing cognitive development. Considering all that was observed and collected through questionnaires and interview, the importance of mediation during activities performed using the software is unquestionable. This was the focus of this study - to analyze the importance of mediation, which was clearly demonstrated.

It should also be stressed the importance of establishing increasing levels of difficulties and of presenting counter-questions (questions asked based on students' answers), which stimulate thinking. Such behavior was adapted during all research activities; it was possible to observe that it enabled students to consciously progress in terms of what was being studied through analysis and reflection. However, stressing this behavior only reinforces the previous idea about the fundamental importance of a well coordinated mediation by the teacher.

The technique of participant observation was very important in the entire process, since it allowed researchers to register observations, generally reflecting on what was occurring. Some perceptions were only possible due to an integration between researchers and students. In addition, the questionnaires and the semi-structured interview complemented the observed data, ensuring a deeper analysis.

The fact that all the activities performed demands time that is often not available for teachers (both in terms of implementing the planning with students and in relation to the time required to prepare investigation activities) was certainly not ignored. However, an experiment such as this reported in the study at least leads to a reflection on the teaching practice of many teachers. How many misjudge that they teaching when they are actually only transmitting information? It should be stressed that the focus here is not on teachers without commitment, but on dedicated people who take their work seriously, although sometimes mistakenly. Thus, it is worth reflecting if spending some time preparing activities that aim at knowledge building is not advantageous after all.

Finally, the students who participated in the study belong to a group of students Mathematics teachers. Therefore, they had the opportunity of having a quite interesting experience not only in terms of learning the mathematical theme, but also in relation to their future teaching practices. Readings are fundamental, but experiences are generally more remarkable-they speak for themselves.

\section{References}

Artigue, M. (2002). Learning mathematics in a CAS environment: The genesis of a reflection about instrumentation and the dialectics between technical and conceptual work. International Journal of Computers for Mathematical Learning, 7, 245-274. doi:10.1023/A:1022103903080

Baldin, Y. Y. (2002). Utilizações diferenciadas de recursos computacionais no ensino de matemática (Differentiated uses of computer resources in the teaching of mathematics). In L. M. Carvalho, \& L. C. Guimarães, (Org). História e Tecnologia no Ensino da Matemática (pp. 29-37). Rio de Janeiro: IME-UERJ.

Baquero, R. (1996). Vigotsky y el aprendizaje escolar. Buenos Aires: Aique Grupo Editor.

Bogdan, R., \& Biklen, S. K. (1998). Qualitative research for education: An introduction to theories and methods. Boston: Allyn and Bacon, Inc.

Borba, M. de C., \& Penteado, M. G. (2005). Informática e educação matemática (Informatics and mathematics education) (3rd ed.) Belo Horizonte: Autêntica.

Bueno-Ravel, L., \& Gueudet, G. (2009). Online resources in mathematics, teachers' geneses and didactical techniques. International Journal of Computers for Mathematical Learning, 14, 1-20. doi:10.1007/s10758-009-9143-0

Cole, M. (1986). The zone of proximal development: Where culture and cognition create each other. In J. Wertsch, (Org.). Culture, communication and cognition: Vygotskian perspective (pp. 146-161). USA: Cambridge University Press.

Cole, M., \& Scribner, S. (1978) Introducion. In L. S. Vygotsky (ed.) Mind in society: The development of higher psychological process (pp. 1-14). United States of America, President and Fellows of Harvard College.

Coll, C. (1990). Un marco de referencia psicológico para la educación escolar: la concepción constructivista del aprendizaje y de la enseñanza. In C. Coll, J. Palácios, \& A. Marchesi, (Org.). Desarrollo psicologico y educacion: psicologia de la educacion escolar, v.2 (pp. 435-453). Madri: Alianza Editorial.

D’Ambrósio U. (2001). Etnomatemática: elo entre as tradições e a modernidade [Ethnomathematics: link between tradition and modernity]. Belo Horizonte: Autêntica.

Doise, W. (1988). El desarrollo social de la inteligencia: compendio histórico. In G. Mugny, \& J. Pérez, (Eds.). Psicología Social del Desarrollo Cognitivo (pp. 47-64). Espanha: Editorial Anthropos.

Fainguelernt, E. (1999). Educação matemática: representação e construção e geometria (Mathematics education: representation, construction and geometry). Porto Alegre: Artes Médicas.

Gil, A. C. (1999). Métodos e Técnicas de Pesquisa Social (Methods and Techniques of Social Research) (5th ed.). São Paulo: Atlas.

Gindis, B. (2003). Remediation through education: Sociocultural theory and children with special needs. In A. Kozulin, B. Gindis, V. S. Ageyev, \& S. M. Miller (Eds.), Vygotsky's educational theory in cultural context (pp. 200-221). New York: Cambridge University Press.

Guven, B. (2008). Using dynamic geometry software to gain insight into a proof. International Journal of Computers for Mathematical Learning, 13, 251-262. doi:10.1007/s10758-008-9129-3

Johnston-Wilder S., \& Pimm D. (Ed.) (2004). Teaching secondary mathematics with ICT. London: Open University Press.

Karpov, Y. (2003). Development Through the lifespan: a neo-vygotskia approach. In A, Kozulin, B. Gindis, V. S. Ageyev, \& S. M. Miller (Eds.), Vygotsky's educational theory in cultural context (pp. 
138-155). New York, NY: Cambridge University Press.

Kozulin, A (2003). Psychological tools and mediated learning. In A. Kozulin, B. Gindis, V. S. Ageyev, \& S. M. Miller (Eds.), Vygotsky's educational theory in cultural context (pp. 15-38). New York: Cambridge University Press.

Laplane, A. L. F. (2000). Interação e silêncio na sala de aula (interaction and silence in the classroom). Ijuí: Editora UNIJUÍ.

Laville, C., \& Dionne, J. A (1997). La construcition dês savoirs: manuel de méthodologie en sciences. Monteral-Canadá: Chenelière/ McGraw-Hill.

Maschietto, M. (2008). Graphic calculators and micro-straightness: analysis of a didactic engineering. International Journal of Computers for Mathematical Learning, 13, 207-230. doi:10.1007/s10758-008-9141-7

Moysés, L. (2007). Aplicações de vygotsky à educação matemática (application of vygotsky to mathematics education) (8th ed.). Campinas-SP: Papirus.

Oliveira, M. K. de (1993). Vygotsky aprendizado e desenvolvimento um processo sócio-histórico (Vygotsky learning and development with a socio-historical process). São Paulo: Scipione.

Passerino, L. M., Koch, S. K. S., Maciel, M., \& Martins, M. del C. (2008). Mediação por meio de evidências no contexto lingüístico em ambientes virtuais de aprendizagem. In XIX Simpósio Brasileiro de Informática na Educação. Fortaleza (CE). Anais ... Fortaleza (CE): Universidade Federal do Ceará, 1, 430-440.

Ponte, J. P. da, Brocado, J., \& Oliveira, H. (2005). Investigações matemáticas na sala de aula (investigations mathematics classroom). Belo Horizonte: Autêntica.

Ponte, J. P. da, Oliveira, H., \& Varandas, J. M. (2003). O contributo das tecnologias de informação e comunicação para o desenvolvimento do conhecimento e da identidade profissional (The contribution of information and communication technologies for development of knowledge and professional identity). In: D. Fiorentini (Ed.), Formação de professores de matemática: Explorando novos caminhos com outros olhares. Campinas: Mercado de Letras, 159192.

Preti, d. (Org.) (2002). Interação na fala e na escrita (Interaction in speech and writing). São Paulo: Humanitas Publicações.

Valentini, C. B., \& Soares, E. M. S. (2005). Fluxos de Interação: uma experiência com ambiente de aprendizagem na Web (Interaction flows: An experience with the learning environment on the Web). In C. B. Valentini, \& E. M. S. Soares, (Org.), Aprendizagem em ambientes virtuais: compartilhando idéias e construindo cenários $v$. 1 (pp. 77-86). Caxias do Sul: EDUCS.

Vygotsky, L. S. (1993). Pensamiento y lenguaje. In A. Alvarez, \& P. Del Rio (Eds), L. S. vygotsky obras escogidas v. II. problemas de psicologia general (pp. 9-348). Madrid: Visor Distribuciones.

Vygotsky, L. S. (1986). Thought and language. Cambridge: Harvard University Press.

Vygotsky, L. S. (1978). Mind in society: The developmente of higher psychological process. United States of America: President and Fellows of Harvard College.

Wertsch, J. (1998). Mind as action. New York, NY: Oxford University Press.

Yin, R. K. (2003). Case study research: Design and methods. Califórnia: Sage Publications. 